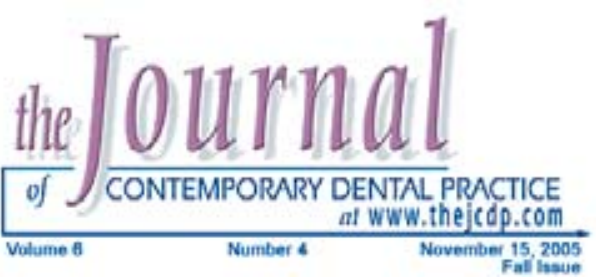

\title{
Fetal Alcohol Syndrome: Anthropometric and Oral Health Status
}

\author{
Sudeshni Naidoo, BDS, LDS.RCS, MDPH, DDPH.RCS, MChD, PhD; \\ Usuf Chikte, BChD, MSc, DHSM, MDent; Ria Laubscher, BComm; \\ Carl Lombard, PhD
}

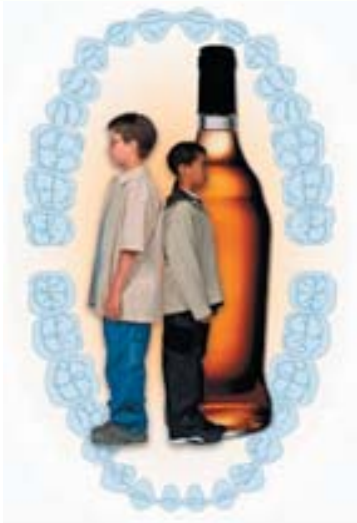

Abstract

The purpose of this study was to analyze the anthropometric measures and oral health status of children with fetal alcohol syndrome (FAS) and compare them to matched controls. The sample of 90 cases (children diagnosed with FAS) and 90 controls were matched for age, gender, and social class. The mean age of the cases was 8.9 years with the controls slightly older at 9.1 years. The results of the anthropometric measurements in respect of weight, height, and head circumference showed significantly lower values for the FAS children when compared to the controls. Several physical abnormalities described in children with FAS were seen in this study. Some of these abnormalities seen in the FAS children included deformities in the small joints of the hand, altered palmar creases, and malformation of the ears.

The prevalence of enamel opacities between FAS and controls was not significantly different and averaged around $15 \%$ for both groups. More than three quarters of both the cases and the controls demonstrated the presence of plaque and almost two-thirds demonstrated gingival bleeding on probing. FAS patients had statistically significantly $(p<0.001)$ more dentofacial anomalies than the controls. The mean decayed, missing, and filled teeth (dmft) score for the FAS sample was slightly higher, though not significantly different from that of the controls, and the decayed component (d) made up the largest part of the index in both groups.

Keywords: Fetal alcohol syndrome, oral health status

Citation: Naidoo S, Chikte U, Laubscher R, Lombard C. Fetal Alcohol Syndrome: Anthropometric and Oral Health Status. J Contemp Dent Pract 2005 November;(6)4:101-115.

(c) Seer Publishing 


\section{Introduction}

About 20 years ago the dangers of maternal alcohol consumption to the developing fetus were generally dismissed. Reports linking maternal alcohol use and fetal growth deficiency were reported from France in the late 1950s. ${ }^{1,2}$ Lemoine et al. ${ }^{3}$ and colleagues described growth deficits, mental retardation, and an unusually high rate of birth defects in 127 children born to alcoholic mothers. Ulleland ${ }^{4}$ reported pre- and postnatal growth deficiency and developmental abnormalities in eight out of 12 children born to alcoholic mothers. Based in part on these reports, Jones and Smith ${ }^{5}$ introduced the term "fetal alcohol syndrome" (FAS) to describe a pattern of abnormalities (distinctive craniofacial disorders and a pattern of altered growth and morphogenesis) found in some children prenatally exposed to alcohol. Their definition was significant as it clearly delineated a clinically recognizable syndrome that was distinct from all other patterns of congenital malformation and was seen exclusively in offspring of mothers who drank large amounts of alcohol during pregnancy.

FAS consists of multi-system abnormalities and is caused by the excessive intake of alcohol during pregnancy. The teratogenic effect of alcohol on humans has now been well established, and FAS is considered to be one of the most important human teratogenic conditions known today. The incidence of FAS varies from nation-to-nation and is dependent upon a population's alcohol consumption. ${ }^{6}$ It occurs with a birth prevalence of between $0.22-0.33$ per 1,000 live births in the $\mathrm{US}^{7,8}$ and an average of 0.97 per 1,000 for the rest of the developed world ${ }^{9}$, which closely approximates to the frequency of more familiar dysmorphic conditions like Down's syndrome. The frequency of FAS in the Western Cape is the highest reported anywhere in the world..$^{10}$

Many investigators have catalogued, quantified, and refined the essential features of FAS over the years and have established the most consistent consequences of heavy maternal drinking during pregnancy are prenatal and postnatal growth deficiency and brain and craniofacial abnormalities. ${ }^{11-19}$

The typical characteristics of FAS are (i) facial abnormalities including microcephaly, narrow forehead, micrognathia, maxillary hypoplasia, flat midface, narrow palpebral fissures, short and small nose, long upper lip with a narrow vermillion border, diminished or absent philtrum, and epicanthal folds, (ii) central nervous system dysfunction with mental retardation ranging from mild to severe, (iii) growth deficiency as in lower weight and height at birth persisting into the postnatal period, and (iv) various cardiovascular and skeletal abnormalities. ${ }^{5}$ Miller et al. ${ }^{20}$ reported opthalmological findings like myopia, microphthalmia, ptosis, strabismus, and blepharophimosis. Many other organ abnormalities have been reported including cleft lip and palate, renal malformations, and deafness.

\section{Characteristics of Fetal Alcohol Syndrome}

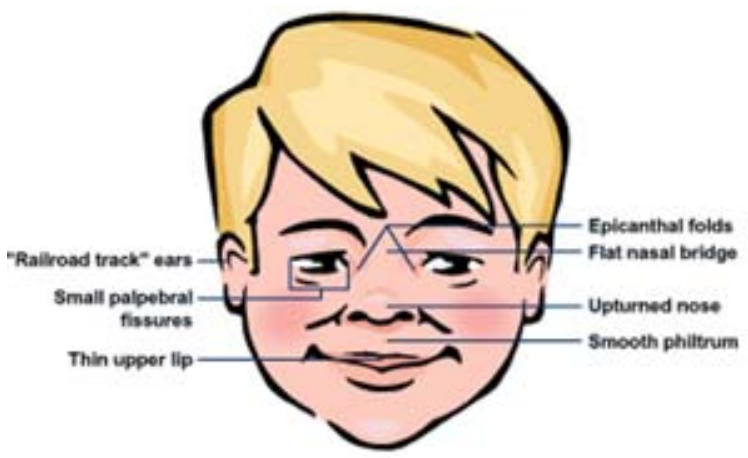

In South Africa medical research into FAS has so far been limited to a few reports ${ }^{21-24}$, none of which are oral or dental related. Despite the wealth of information related to the medical aspects of FAS, it was clear from a review of the literature there is a paucity of literature in the dental field. This paper presents findings from a case-control study of the anthropometric and oral and dental manifestations associated with FAS.

\section{Materials And Methods}

The research was a descriptive, case-control, cross-sectional study. The population included all children in Grades 1 to 12 of the 13 primary schools in Wellington, South Africa. The sample size was based on an estimated prevalence of $10 \%$ for FAS and a confidence limit of $3-15 \%$. All children diagnosed with FAS were included in the study.

Children with signed, informed consent were examined, and the examiner was blind as to whether the child was a case or a control. Children were weighed, and their height and head 


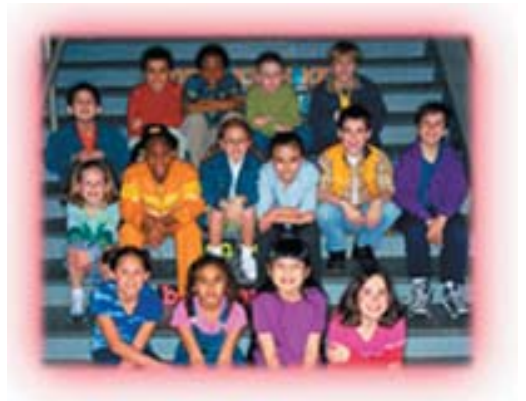

circumference were measured. Photographs and radiographs were taken, followed by a thorough oral examination. For each child, the following information was recorded on the data capture sheet: a record number, name, date of birth, gender, head circumference, weight and height, enamel opacities, plaque index, gingival bleeding index, dentition status and treatment need (DMFS/dmfs), oral mucosal lesions, and dentofacial anomalies.

Various anthropmetric indices were used to assess growth status. ${ }^{25}$ Height, weight, and head circumference were measured and assessed against head circumference and weight-versusheight charts. Examinations were carried out in the dental clinic with the patient seated in a dental chair using normal examination light. The modified developmental defects of enamel (DDE) index was used to describe any enamel opacities that were present. ${ }^{26}$

The plaque index of Silness and Lö ${ }^{27}$ was used to assess the thickness of plaque at the gingival area. It is sensitive to small changes, can be transformed easily to record the presence or absence of plaque, and is widely used in epidemiological research. ${ }^{28}$ It was selected as a precise and reliable index. The gingival bleeding index of Carter and Barnes ${ }^{29}$ was used to record the presence or absence of gingival inflammation as determined by bleeding from inter-proximal gingival sulci. The decayed, missing, and filled tooth surfaces DMFS ${ }^{29}$ and the $\mathrm{dmfs}^{30}$ indices were used to determine dental caries experience, past and present, by recording tooth surfaces involved. Third molars were not counted. A systematic approach to the assessment of the dentition status and treatment was adopted using the World Health Organization (WHO) Guidelines to Oral Health Surveys. ${ }^{26}$ Any abnormalities of the mucosa or of the gingiva were recorded on the data capture sheet. ${ }^{32}$ The following dentofacial anomalies were recorded: crowding in the incisal segments, spacing in the incisal segments, diastema, anterior maxillary overjet, anterior mandibular overjet, vertical anterior openbite, and anterior-posterior molar relationships.

\section{Statistical Methods}

Since the anthropometric data were from children of different ages and genders, all measurements were standardized to allow for comparisons by converting all the data to "standard" or Z scores. This process was accomplished in the usual manner by subtracting the population mean from the individual measurement value and dividing by the population standard deviation (SD). Descriptive analysis involved computing the mean, SD, minimum, maximum, and the range of the clinical and radiographic parameters.

\section{Continuous Data}

Continuous data were compared by using the Student's t-test. When faced with small numbers, the more robust non-parametric Mann-Whitney $U$ test which does not require the data to be analysed to follow any specific distribution was used. In most cases the Student's t-test was used, but where there was uncertainty about the distribution of the data the Mann-Whitney $U$ test was also applied.

\section{Categorical Data}

The chi-squared $\left(\mathrm{x}^{2}\right)$ test for determining association of the categorical variables and bivariate analysis using the Student's t-test was performed to compare categorical variables (such as age, gender).

\section{Results}

\section{Demography}

The sample of 90 cases (children diagnosed with FAS) and 90 controls were matched for age, gender, and social class. The mean age of the cases was 8.9 years (SD 1.29) with the controls slightly older at 9.1 years (SD 1.29). This was not significant $(p=0.3363)$, and the age ranges for both the groups were the same, i.e., 6.4 years for both the case and the controls.

\section{Anthropometry}

The results of the anthropometric measurements in respect to weight, height, and head 
circumference showed significantly lower values for the FAS children when compared to the controls (Table 1). The weight-for-age ratio of the FAS cases (21.53) was significantly lower than for the controls (26.88) at a probability level of $p<0.001$. Similarly, the height-for-age of the FAS subjects (121.11) was lower than that of the controls (126.78). The head circumference differed significantly between the two groups $(p<0.0001)$. The mean head circumference of the FAS children was $49.03 \mathrm{~cm}$ and $51.53 \mathrm{~cm}$ for the controls (Table 1).

Table 2 shows statistically significantly differences $(p<0.0001)$ for both weight-for-age $z$-scores (WAZ) and height-for-age z-scores (HAZ) between the FAS children and the controls.

The minor anomalies that were found in the total sample $(n=180)$ are shown in Table 3 . The common malformations of the fingers include clinodactyly, camptodactyly, and the incomplete rotation of the elbow, causing limited supination. All the malformations of the hands were found to be statistically significantly different between the FAS and the control children. Clinodactyly is the curving of a finger to one side, usually toward the midline. Camptodactyly occurs when the proximal interphalangeal joints are held in a partially flexed position, sometimes with thickened connective tissue on the volar surface. In addition significantly more FAS children manifested growth retardation and some structural abnormality $(p<0.0001)$.

\section{Oral Health}

More than three quarters of both the cases and the controls demonstrated the presence of plaque. Almost two-thirds of both case and control groups had gingival bleeding on probing. The prevalence of oral mucosal lesions between FAS and controls was not statistically significant

Table 1. Descriptive statistics of anthropometric measurements: mean (SD).

\begin{tabular}{|c|c|c|c|}
\hline Variable & Controls $(\mathrm{n}=90)$ & FAS $(\mathrm{n}=90)$ & $\begin{array}{c}\text { Student's T-test (p- } \\
\text { value) }\end{array}$ \\
\hline Weight $(\mathrm{kg})$ & $26.88(\mathrm{SD} \mathrm{5.35)}$ & $21.53($ SD 3.25) & $<0.0001$ \\
\hline Height $(\mathrm{cm})$ & $126.79($ SD 2.53) & $121.11($ SD 5.62) & $<0.0001$ \\
\hline $\begin{array}{c}\text { Head circumference } \\
(\mathrm{cm})\end{array}$ & $51.53($ SD 1.29) & 49.03 (SD 1.26) & $<0.0001$ \\
\hline
\end{tabular}

Table 2. Height-for-age z-score (HAZ), Weight-for-age z-score (WAZ).

\begin{tabular}{|c|c|c|}
\hline Characterlstic & Control ( $\mathrm{n}=90)$ & FAS ( $\mathrm{n}=90)$ \\
\hline WAZ (mean) & -0.519 (SD 0.874) & -1.637 (SD 0.685) \\
\hline p value & $<0.0001$ & $-1.775($ SD 0.807) \\
\hline HAZ (mean) & -0.957 (SD 0.977) & \\
\hline pvalue & $<0.0001$ \\
\hline
\end{tabular}

Table 3. Clinical findings - minor anomalies.

\begin{tabular}{|c|c|c|c|}
\hline Characteristic & $\begin{array}{c}\text { Control }(\mathrm{n}=90) \\
\mathrm{n}(\%)\end{array}$ & $\begin{array}{c}\text { FAS }(\mathrm{n}=90) \\
\mathrm{n}(\%)\end{array}$ & p value \\
\hline Hands & \multicolumn{3}{|l|}{} \\
\hline Clinodactyly & $5(5.6)$ & $36(40.0)$ & $<0.0001$ \\
\hline Camptodactyly & $0(0)$ & $23(25.6)$ & $<0.0001$ \\
\hline Limited supination & $0(0)$ & $12(13.3)$ & 0.0003 \\
\hline $\begin{array}{c}\text { Anomalous palmar } \\
\text { creases }\end{array}$ & $5(5.6)$ & $48(53.3)$ & $<0.0001$ \\
\hline $\begin{array}{c}\text { Hypoplasia: terminal } \\
\text { phalanges }\end{array}$ & $2(2.2)$ & $15(16.7)$ & 0.0009 \\
\hline Other abnormalities & $1(1.1)$ & $76(84.4)$ & $<0.0001$ \\
\hline Growth deficiency & $5(5.6)$ & $80(88.9)$ & $<0.0001$ \\
\hline Structural abnomality & \multicolumn{4}{|l|}{}
\end{tabular}


and ranged from $12 \%$ for the control group to $21 \%$ for the cases. Overall, $16.6 \%$ of the sample had one or more oral condition. Most frequently seen were dentoavleolar abscesses largely related to carious teeth and traumatic lesions. Other lesions included ulcers (herpetic and aphthous) and angular cheilitis.

The prevalence of enamel opacities between FAS and controls was approximately $15 \%$ for both groups. The opacities were seen largely in the maxillary central incisor and lower first molar teeth. Most of the opacities were demarcated, diffuse, or of the hypoplastic variety.

Dentofacial anomalies were investigated in respect to crowding of incisors, spaces between incisors, presence of diastemas, maxillary overjets, mandibular overjets, and openbites (Table 4). The cases had statistically significantly $(p<0.001)$ more dentofacial anomalies than the controls, and these occurred most commonly as crowding of the incisors, maxillary overjet, and openbite.

\section{Tooth and Eruption Disturbances}

Congenitally absent teeth were seen in five of the FAS children and two of the controls (Table 5). Of the five FAS children, four had congenitally absent premolars and one a congenitally missing lateral incisor. The control children had a second premolar and first permanent molar absent. In addition to the missing teeth, three FAS children presented with a transposed central incisor ${ }^{21}$, "peg laterals," and taurodontic mandibular first molars. There were no significant differences between the cases and the controls.

\section{Caries Status}

A summary of the overall caries status of the cases and controls is shown in Table 6. Thirty nine children $(21.67 \%)$ of the total sample were caries-free. In the following tables DMFT and dmft refer to the permanent and the primary dentition caries status, respectively. The mean $\mathrm{dmft}$ score for the FAS sample was slightly more, though not significantly different, than that of the controls; the decayed component (d) made up the largest part of the index in both groups. None of the FAS children had any missing (due to caries) teeth nor filled teeth. For the controls, a similar pattern was observed. The mean DMFT score for the FAS sample was slightly lower, and not significantly different, from than that of the controls, and the decayed component (D) made up the largest part of the index in both groups. Missing and filled teeth were rarely found in both groups. The dmf scores for both case and controls, at various age intervals, showed no discernable difference between the dmft of the cases and controls for the various age groups. For the mean DMFT scores at various age intervals, a gradual increase in the DMFT score with increasing age was found. The $\mathrm{dmft}$ score for the FAS males was 2.18 compared to 1.64 of the controls and 1.40 for the FAS females compared to 1.62 for their controls. The

Table 4. $X^{2}$ frequency of dentofacial anomalies.

\begin{tabular}{|c|c|c|c|c|c|c|}
\hline Feature & $\begin{array}{l}\text { Crowded } \\
\text { Incisors }\end{array}$ & $\begin{array}{l}\text { Spaced } \\
\text { Incisors }\end{array}$ & Diastema & $\begin{array}{c}\text { Maxillary } \\
\text { overjet }\end{array}$ & $\begin{array}{c}\text { Mandibular } \\
\text { Overjet }\end{array}$ & Openbite \\
\hline & $n(\%)$ & $n(\%)$ & $n(\%)$ & $n(\%)$ & $n(\%)$ & $n(\%)$ \\
\hline \begin{tabular}{|c} 
Control $(n=$ \\
$90)$
\end{tabular} & $1(16.7)$ & $2(66.7)$ & $1(33.3)$ & $6(33.3)$ & $5(62.5)$ & $7(31.2)$ \\
\hline Case $(n=90)$ & $5(83.3)$ & $1(33.3)$ & $2(66.7)$ & $12(66.7)$ & $3(37.5)$ & $15(68.8)$ \\
\hline Total & $6(100)$ & $3(100)$ & $3(100)$ & $18(100)$ & $8(100)$ & $22(100)$ \\
\hline
\end{tabular}

Table 5. Tooth disturbances.

\begin{tabular}{|c|c|c|c|c|c|c|}
\hline Feature & $\begin{array}{c}\text { Disturbance } \\
\text { present }\end{array}$ & $\begin{array}{c}\text { Absent } \\
\text { teeth }\end{array}$ & $\begin{array}{c}\text { Absent } \\
\text { laterals }\end{array}$ & $\begin{array}{c}\text { Absent } \\
\text { premolars }\end{array}$ & $\begin{array}{c}\text { Absent } \\
\text { molars }\end{array}$ & Other \\
\hline $\mathbf{n}(\%)$ & $\mathbf{n}(\%)$ & $\mathbf{n}(\%)$ & $\mathbf{n}(\%)$ & $\mathbf{n}(\%)$ & $\mathbf{n}(\%)$ \\
\hline $\begin{array}{c}\text { Control }(\mathbf{n}= \\
90)\end{array}$ & $2(20)$ & $2(29)$ & $0(0)$ & $1(20)$ & $1(100)$ & $0(0)$ \\
\hline Case $(\mathbf{n}=90)$ & $8(80)$ & $5(71)$ & $1(100)$ & $4(80)$ & $0(0)$ & $3(100)$ \\
\hline Total & 10 & $7(100)$ & $1(100)$ & $5(100)$ & $1(100)$ & $3(100)$ \\
\hline
\end{tabular}


Table 6. Summary of caries status.

\begin{tabular}{|c|c|c|c|}
\hline Characteristic & Control $(\mathrm{n}=90)$ & FAS $(\mathrm{n}=90)$ & \\
\hline dmft & Mean (SD) & Mean (SD) & p value \\
\hline d & $1.56(1.84)$ & $1.79(1.93)$ & 0.4085 \\
\hline m & $0.02(0.14)$ & 0 & 0.1585 \\
\hline f & $0.06(0.43)$ & 0 & 0.2272 \\
\hline dmft & $1.63(1.91)$ & $1.79(1.93)$ & 0.5880 \\
\hline DMFT & Mean (SD) & Mean (SD) & p value \\
\hline D & $0.90(1.37)$ & $0.71(1.06)$ & 0.3020 \\
\hline M & $0.03(0.23)$ & $0.01(0.10)$ & 0.4140 \\
\hline F & $0.01(0.10)$ & $0.04(0.42)$ & 0.4686 \\
\hline DMFT & $0.94(1.40)$ & $0.77(1.1)$ & 0.3454 \\
\hline
\end{tabular}

\section{* significant}

mean decayed teeth values made up the greatest proportion of this score in both sexes, and the mean for FAS males was higher (2.18) than that for the FAS females (1.40). Both the missing and filled scores were zero for both the FAS males and females and were consequently disregarded for further comparisons. The differences between the $\mathrm{d}$ and $\mathrm{dmft}$ between the males and females were not found to be statistically significant.

The DMFT score for the FAS males was 0.60 compared to 1.11 of the controls and 0.93 for the FAS females compared to 0.78 for their controls. The differences between the DMFT, the D, M, and the F components were not found to be statistically significant for cases and controls for males and females. The mean decayed teeth values made up the greatest proportion of this score in both sexes, and the D component in the FAS females was slightly higher (0.82) than that of the FAS males (0.60) and the female controls (0.73). Both the missing and filled scores were zero for the FAS males. The differences between the $D$ and DMFT between the males and females were not found to be statistically significant.

\section{Discussion}

A total of 90 FAS cases and 90 controls were matched for age, gender, and social class and formed the sample of this study.

\section{Anthropometry}

Forty two percent of the FAS sample manifested growth retardation, and this was statistically significant $(p<0.0001)$ when compared to their controls

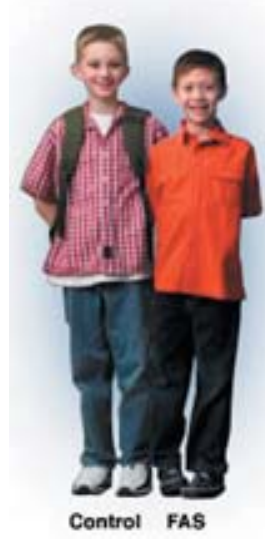

(Table 1). Children with FAS commonly have a low birth weight and remain small for their age. This study confirms the findings of Jones et al. ${ }^{33}$ that the intrauterine growth retardation results in weights, lengths, and head circumferences below the tenth percentile. The occurrence of compensatory (catch-up) growth has been debated. Jones et al. ${ }^{34}$ reported the absence of linear and head circumference compensatory growth, and Hanson et al. ${ }^{35}$ concurred with this view. However, Lemoine et al. ${ }^{3}$ suggested it might improve in later childhood. Jackson and Hussain ${ }^{35}$ showed compensatory growth in stature, weight, and head circumference can take place in some circumstances. They also showed there was a delay in bone age. This was in disagreement with Clarren and Smith ${ }^{13}$ who stated bone age is usually normal in FAS. Hanson et al. ${ }^{11}$ reported postnatal weight gain was poor, becoming underweight for length; however, the Jackson and Hussain ${ }^{36}$ study suggested there is a long-term tendency to gain weight more than stature.

Based on the anthropometry results, the FAS children weighed significantly less than the controls, were shorter, and had significantly smaller head circumferences. This corresponds well to what is found in the literature..$^{37-39}$ Low weight-for-age indicates a state of acute malnutrition of a short-term nature, while low height-for-age indicates stunted growth which reflects a process of failure to reach linear growth potential as a result of sub-optimal health and/ or nutrition conditions. On a population basis, high levels of stunting are associated with poor socio-economic conditions and the increased risk of frequent and early exposure to adverse 
conditions such as illness and/or inappropriate feeding practices ${ }^{26}$; however, the matching for gender and age in this study would have negated these factors.

Head circumference differed significantly between the two groups $(p<0.0001)$, and the three diagnostic measurements (palpebral fissure length, inter-pupillary distance, and inner canthal distance) were all influenced by head circumference. Results from this study corroborate previous observations that individuals diagnosed with FAS exhibit, on average, small heads (microcephaly), small faces, short palpebral

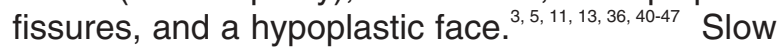
growth in head circumference usually indicates slow brain growth. ${ }^{37,48}$ Microcephaly, resulting from abnormal glial migrations and diminished white matter, is often the earliest sign of central nervous system involvement. The enlargement of head circumference and corresponding brain weight is an important goal of medical care in children with FAS. In the present study there was a statically significant correlation between weight and head circumference for both the cases and the controls. Controls were heavier and had markedly larger head circumferences when compared to the FAS children. Majewski ${ }^{37}$ studied the influence of weight on head circumference in FAS patients and found heavier children had markedly larger head circumferences, reflecting possible correlation between weight and brain growth. However, those differences were nearly the same as at birth, and the catch-up growth of head circumference in heavier children was not observed to be greater than in underweight children; so the author concluded his patients with the greater weight did not have better brain growth. Nevertheless, it is recommended head circumference should be increased by early and high-calorie feeding, especially in the first six months of life. Increased head circumference parallels increased brain growth ${ }^{49}$ and probably parallels improved mental development as a result of increase in myelinization and growth of dendrites and synapses.

\section{Infrequent Malformations and Fluctuating Asymmetry}

The pattern of physical abnormalities in the FAS includes subtle abnormalities of the face, an increasing frequency of malformations, congenital cardiac defects (especially atrial and ventricular septal defects), anomalies of the urinary tract, and genitals and psychomotor disturbances (fine motor dysfunctions and poor standardized performance tasks). Abnormalities of the limbs and joints include deformities in the small joints of the hand. In the hands palmar crease patterns appear to be altered. In FAS children a hockey stick crease - where the distal transverse crease runs quite horizontally across the postaxial palm and then abruptly angles distally to exit between the index and middle finger - is often seen.

In addition to the characteristic dysmorphic facial features FAS children in this study were found to have anomalous palmar creases and limited supination. In bilaterally symmetrical structures antimeres should ideally develop as mirror images of one another, largely because the genetic information for both sides is the same. ${ }^{50}$ The degree of phenotypic similarity reached by paired organs is governed by the epigenetic processes that operate during morphogenesis. ${ }^{51-53}$ Failure of this system in the face of environmental disturbances (referred to as "developmental noise") results in fluctuating asymmetry, the magnitude of which may be used as a measure of individual developmental stability. ${ }^{54}$

Assessment of fluctuating asymmetry has long been utilized to estimate the degree of environmental or genetic stress in the developing embryo. ${ }^{55,56}$ In the practice of dysmorphology fluctuating asymmetry has not been commonly utilized as a marker for assessing abnormal human morphogenesis. Rather the presence or absence of minor anomalies is utilized to assess the degree of developmental instability in the embryo.

A minor anomaly is defined as an unusual morphologic feature found in less than $45 \%$ of the general population, which is of no serious medical significance to the affected individual (Jones, 1988). ${ }^{57}$ They may be malformations (structural defects arising from intrinsically abnormal developmental processes), deformations (abnormal structures resulting from non-disruptive mechanical forces applied to a once normally formed part), or disruptions (structural defects) arising from destruction of a once normally formed part). ${ }^{58}$ 
Minor anomalies have been used clinically in dysmorphology in a variety of ways: firstly, some minor anomalies may be the external 'red flags' indicating the presence of specific occult major anomalies; secondly, patterns of minor anomalies constitute the majority of features by which multiple malformation syndromes occur; and lastly, three or more minor anomalies may be a non-specific indicator of an occult major anomaly. ${ }^{55}$ In this study FAS children had statistically significantly more dentofacial anomalies than the control children.

A variety of ear malformations in the FAS children were found in this study. Church and Gerkin ${ }^{59}$ and Church et al. ${ }^{60}$ found high rates of peripheral and central hearing disorders in FAS children. These rates exceeded those reported for the general paediatric population ${ }^{61}$, but were similar to and even exceeded the rates observed in other groups of children with craniofacial anomalies. ${ }^{62}$ The anthropometric configuration of the face in a child with FAS results in a "shallow angle to the eustachian tubes," discouraging middle ear drainage. Hence, these may be conductive hearing loss due to effusion or infection and sensorineural hearing loss (due to direct teratogenic damage) in children with FAS.

Other types of hearing disorders associated with prenatal alcohol exposure include delayed maturation of the peripheral and brainstem auditory pathways and a high incidence of intermittent conductive hearing loss. ${ }^{63}$ FAS patients frequently suffer from various language and speech disorders, such as poor receptive and expressive language skills, slurred and monotonous speech, articulation, and fluency problems. ${ }^{63}$ Central and peripheral hearing disorders, as well as dentofacial defects and mental impairment, may contribute to these language and speech disorders.

Abnormalities of the limbs and joints are seen much more frequently in children with FAS than the general population, and this is shown in the present study where findings related to the infrequent malformations and anomalies for example, clinodactyly, camptodactyly, and abnormal palmar creases were all statistically significant when compared with the controls. These findings were also reported by Aase. ${ }^{45}$
Abnormalities of facial structures with embryonic origins in the cranial neural crest appear to share common causal pathways, including the teratogenic effects of ethanol. Craniofacial malformations and clefts are well known in animal models of ethanol-induced teratogenesis. Kotch and Sulik ${ }^{17}$ observed a pattern of excessive cell death at the rim of the anterior neural plate in mouse embryos within 12 hours of ethanol exposure and have proposed early insult to selected cell populations may account for some of the human malformations.

Clefts are likely to have multiple genetic and environmental causes. Evidence of geneenvironment interactions in the aetiology of clefts have emerged ${ }^{64}$, and it is possible maternal alcohol exposure interacts with genetic or environmental factors. It has been proposed ethanol acts as a competitive inhibitor of $\mathrm{ADH}$ catalysed retinal oxidation in embryonic tissues, resulting in disruptions in the distribution of retinoic acid needed to specify spatial patterns. ${ }^{65,66}$

The relationship in humans between maternal alcohol exposure and clefts remains unclear. Niebyl et al. ${ }^{67}$ found no association between maternal alcohol use and clefts, but their study had limited statistical power with only 59 cases. However, it has been documented alcohol use during pregnancy may be a cause of isolated cleft lip with or without cleft palate. Werler et al. ${ }^{67}$ found a threefold elevated risk of cleft lip with or without cleft palate in infants whose mothers reported an average of five or more drinks per drinking day. This exposure level is not easily interpreted and few of the mothers were in the highest level of exposure.

Munger et al. ${ }^{69}$ reported maternal alcohol use during pregnancy was found to be associated with an increased risk of isolated cleft lip without or without cleft palate. When compared to women who did not drink alcohol during pregnancy, the relative odds of isolated offspring having a cleft lip with or without cleft palate rose with increasing level of maternal drinking. Adjustment for maternal smoking, vitamin use, education, and household income did not substantially alter these results. No significant association was found between alcohol use and isolated cleft palate or clefts in children with 
multiple birth defects. Clefts appear not to be a major feature of the FAS, although they may occasionally be present, but clefts may be part of the broader spectrum of the more common and less severe fetal effects of maternal alcohol use. ${ }^{37}$

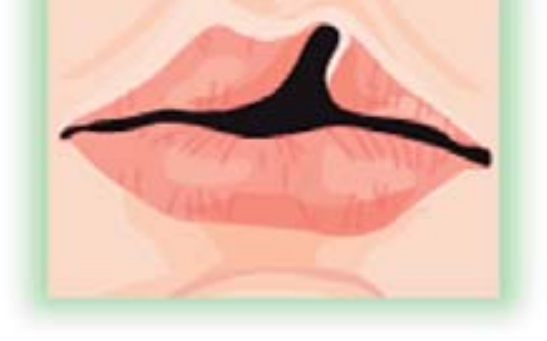

Despite the fact in this present study no children were seen with orofacial cleft birth defects possibly because of the small sample size, but in view of the graded increase in the risk of isolated cleft lip with or without cleft palate with increasing amounts of alcohol consumed, ${ }^{69}$ it would be prudent to consider there may be no safe level of alcohol consumption during pregnancy. Women in their reproductive years face a dilemma regarding their decision to drink alcohol or not because the susceptible period for many of the teratogenic effects of alcohol is in the first few weeks of pregnancy, before many women realize they are pregnant. The hazards of alcohol consumption should be frankly discussed with all women who may become pregnant as this information makes a strong case for the expansion of preconceptual counselling.

\section{Plaque Scores and Gingival Bleeding}

The levels of plaque and gingival bleeding were high, and this was not an unexpected finding since these children come from backgrounds where oral hygiene (toothbrushing) is not a high priority. It was surmised that due to the behavioural and neurological problems children with FAS have, poor oral hygiene may have been a reflection of this. However, there is a threshold level beyond which one cannot discriminate.

\section{Oral Soft Tissue Lesions}

The results of this examination showed $16.6 \%$ of the children had one or more soft tissue lesions. This figure is considerably lower than the figure (32.9\%) reported by Arendorf and van der Ross ${ }^{70}$, who examined 1051 black pre-school children, aged between 18 and 80 months, in and around Cape Town. In this study there was no difference between the FAS group and the controls. The dentoalveolar abscess was the most common lesion seen. Other lesions seen included angular cheilitis, herpetic, and aphthous ulcerations.

\section{Enamel Opacities}

The more premature the birth and the lower the birth weight, the higher the tendency for the child to from systemic derangements which can affect dental development adversely. ${ }^{71,72}$ Enamel hypoplasia is increasingly recognized as a biomarker of a range of systemic disturbances including intra-uterine malnutrition, maternal stressors, and infectious diseases in the first years of life..$^{71,73-74}$ Various reports have documented enamel hypoplasia in children with FAS. $^{75-77}$ The prevalence of enamel opacities in this study ranged between $15 \%$ and $16 \%$ for both groups. This concurs with what was reported by Hargreaves et al. ${ }^{74}$ in a general population of children from the four ethnic groups (White, Indian, Coloured, and Black) where hypoplasia ranged from $8.2-19.7 \%$.

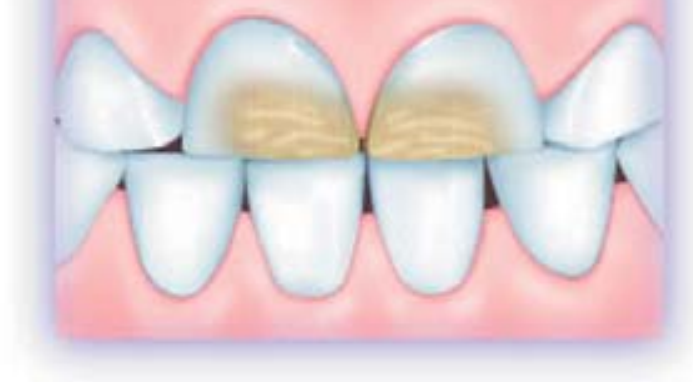

Children of color had a high prevalence of $16 \%$. In the present study the opacities were seen largely in the maxillary central incisors and lower first molar teeth. This too concurs with Hargreaves et al. $^{74}$ where maxillary central incisors showed the most enamel defects. Pimlott et al. ${ }^{71}$ and Dummer et al. ${ }^{78}$ described a much higher involvement of the maxillary than of the mandibular permanent teeth; no satisfactory explanation for this observation has been reported. 


\section{Caries Status}

Overall the analysis of the caries data for this study in respect of differences between cases and controls was found to be unremarkable. The lack of difference in the primary and permanent dentitions between the cases and controls could have been anticipated in this population because of the high prevalence of dental caries among children from the Western Cape. ${ }^{79}$ The observed decline of caries experience in primary teeth with increasing age can be attributed to exfoliation of teeth. The dmft was relatively low, with a predominance of the decayed (d) component for both cases and controls. Together with an almost complete absence of any missing or filled teeth, this may be ascribed to the lack of access to care and possibly perceptions about oral health and dietary as well as oral hygiene habits.

The DMFT overall for the controls (0.94) was higher, though not significant, than the cases (0.77). As expected, for both cases and controls there was an increase in DMFT with increasing age. However, the increments were larger for the controls. This is possibly due to delayed eruption of the permanent dentition in the FAS children, as shown by the difference in dental age between the cases and the controls.

It is difficult to explain the differences in $\mathrm{dmft} /$ DMFT between males and females, both in cases and controls. The dmft for the females was lower than that of the males. The reverse is true for the DMFT. This could be explained possibly by the early exfoliation of primary teeth and earlier eruption of permanent teeth in females compared to males. ${ }^{80}$

Direct comparison of dmft/DMFT scores of this study with similar population groups in South Africa is problematic because of the lack of detail of sample selection, age frequencies, and methods expressing caries experience in these studies. Generally, the dmft/DMFT scores were lower or similar to those found in comparable groups in the Western Cape. ${ }^{81}$ In this study the dmft scores for both the case and control were lower than 3 for the lowest age category (7-8 years) and much lower than the dmft obtained for Western Cape (5.78 SD 4.31). It should be noted, however, the data reflected in the Provincial sample only refers to 6-year-olds.
For the mean DMFT, the controls (2.83) and the Provincial (2.2 SD 2.54) 12-year-old sample are similar. ${ }^{79}$

\section{Dentofacial Anomalies}

Prior observations on the dentofacial anomalies of FAS have included the presence of crossbite and overbite ${ }^{82,83}$, hypoplastic teeth, and a high incidence of caries, ${ }^{84-86}$ delayed dentition, and hypoplastic enamel. ${ }^{36}$ In this study the cases had statistically significantly more dentofacial anomalies than the controls. The most frequently occurring anomalies were crowded incisors, maxillary overjet, and openbites.

When the author explored the possible reasons for these conditions with the children, nearly all reported they engaged in a thumb-sucking habit. In thumbsuckers the bases of the maxillae are on average anteriorly displaced and longer in comparison with controls. The incidence of malocclusion is also higher for thumbsuckers. The most common effects of a thumbsucking habit on the dentition are open bite, narrow upper arch, and a crossbite. ${ }^{.7}$

Church et al. ${ }^{60}$ observed in FAS patients high incidences of dental crowding, crossbite, overjet, delayed dentition, absent and displaced teeth, and malaligned and rotated teeth. This could have been due to the fact their patients were recruited from an Oral Cleft Centre at the Children's Hospital in Michigan and 52\% had some form of cleft palate. However, this was not the case in a study by Riekman ${ }^{88}$ who found anomalous dental conditions between the two groups (cases and controls) to be similar. In addition the incidence of crossbite was also unremarkable.

Dentofacial anomalies were found to be more frequent in FAS patients, yet they are often ignored and undescribed. These anomalies, because of their pronounced and prevalent nature, are important not only because they can influence speech but because they may require orthodontics and plastic surgery and can aid with FAS diagnosis. The relationship between hearing, speech, language, and dentofacial disorders in FAS patients need to be better documented and described, so as to aid diagnosis and treatment. 


\section{Conclusion}

The findings from this paper describing the anthropometric and oral health status of the hard and soft tissues of the mouth were not as noteworthy as was expected. There were no significant age differences between the two groups in the sample, and the results of the anthropometric measurements in respect of weight, height, and head circumference showed significantly lower values for the FAS children when compared to the controls. Almost all of the physical abnormalities described in children with FAS were seen in this study. Some of these abnormalities included derformities in the small joints of the hand, altered palmar creases, and malformation of the ears.

The findings of this study are remarkably similar to the few studies carried out abroad that have documented orofacial manifestations.

The data from this study suggest craniofacial anthropometry still has a place in the field to quickly and reliably identify children with subtle alcohol effects. The oral health status of the hard and soft tissues were not as noteworthy as was expected, and this could be ascribed to the fact the most vulnerable time for most of the developmental defects associated with the developing teeth occurs during the first year of life. ${ }^{74}$ However, the prevalence of dent-alveolar abscesses was a cause for concern and reflects chronic infection and absence of treatment.
There is a need for large-scale, longitudinal, standardized studies to elucidate the finer aspects of the onslaught of alcohol on the development of the craniofacial and oro-dental apparatus of the developing fetus. These studies would need to incorporate biological and genetic variables that exacerbate fetal damage that could not be included in the present study.

It has been shown from the results of this study there are two areas of particular interest to the dentist: the craniofacial anomalies and the medical problems that may affect the dental management of these patients. The awareness and recognition of patients with FAS is important so they can be correctly diagnosed and referred appropriately. They are likely to have maxillary hypoplasia and micrognathia. Any of these may necessitate follow-up for malocclusion resulting from skeletal disharmonies. Among the medical problems are deficiencies in growth and intelligence. Because of the various congenital cardiac defects (especially atrial and ventricular valvular defects), the patient's medical practitioner needs to be consulted on the patient's susceptibility to subacute bacterial endocarditis and the need for prophylaxis prior to dental treatment. Since the children are mentally challenged, there may be behaviour management problems that are best treated with behaviour management and/or premedication.

\section{References}

1. Lecomte M. Elements d'heredopathologie. Scalpel 1950; 103:113-4.

2. Christiaens L, Mizon JP, Delmarle G. Sur la descendance des alcoholiques. Ann Pediat 1960; 36:37-42.

3. Lemoine P, Harousseau H, Borteyru JP, et al. Les enfants de parents alcooliques: Anomalies observees a propos de 127 cas. Arch Fr Pediat 1968; 25: 830-31.

4. Ulleland C. The offspring of alcoholic mothers. Annals of the New York Academy of Sciences 1972; 197:167-69.

5. Jones KL, Smith DW. Recognition of the fetal alcohol syndrome in early infancy. Lancet 1973; II: 99-1001.

6. Carones F, Brancato R, Venturi E, et al. Corneal endothelial anomalies in Fetal Alcohol Syndrome. Arch Opthalmol 1992; 110:1128-31.

7. Abel EL, Sokol RJ. A revised conservative estimate of the incidence of FAS and its economic impact. Alcoholism Clin Exp Res 1991; 15:514-24.

8. Abel EL, Sokol RJ. Incidence of fetal alcohol syndrome and economic impact of FAS related anomalies. Drug Alcohol Depend 1987; 19:51-70.

9. Abel EL. An update on incidence of FAS: FAS is not an equal opportunity birth defect. Neurotoxicol Teratol 1995; 17:437-43. 
10. Viljoen D. Fetal alcohol syndrome in the Western Cape. Substance Abuse: Research and other initiatives in South Africa (Part 2). MRC: Urban Health and Development Bulletin 1999; 2:19-20.

11. Hanson JW, Jones KL, Smith DW. Fetal Alcohol Syndrome. Experience with 41 patients. JAMA 1976; 235:1458-60.

12. Chernoff GF. The fetal alcohol syndrome in mice: an animal model. Teratology 1977; 15:223-9.

13. Clarren SK, Smith DW. The fetal alcohol syndrome. New Engl J Med 1978; 298:1063-67.

14. Clarren SK, Alvord EC, Sumi SM, et al. Brain malformations related to prenatal exposure to ethanol. J Pediatr 1978; 92:64-7.

15. Streissguth AP, Landesman-Dwyer S, Martin JC. Teratogenic effects of alcohol in humans and laboratory animals. Science 1980; 209:353-61.

16. Sulik KK, Johnston MC, Daft PA, et al. Fetal alcohol syndrome and DiGeorge anomaly: critical alcohol exposure periods for craniofacial malformations as illustrated in an animal model. Am J Med Gent 1986; 2(suppl): 97-112.

17. Kotch LE, Sulik KK. Experimental fetal alcohol syndrome: proposed pathogenic basis for a variety of associated facial and brain anomalies. Am J Med Genet 1992; 44:168-76.

18. Coles CD. Critical periods for prenatal alcohol exposure. Alcohol Health and Research World 1994; 18: 2-9.

19. Weston WM, Greene RM, Uberti M, et al. Ethanol effects on craniofacial growth and development: implications for study of the fetal alcohol syndrome. Alcohol Clin Exp Res 1994;18: 177-82.

20. Miller M, Israel J, Cuttom J. Fetal Alcohol Syndrome. J Pediatr Opthalmol Strabismus 1981; 18: 11-15.

21. Beyers N, Moosa, A. The fetal alcohol syndrome. SAMJ 1978; 54:575-8.

22. Jaffer Z, Nelson M, Beighton P. Bone fusion in fetal alcohol syndrome. J Bone Joint Surg 1981; 63B: 69-71.

23. Palmer C. Fetal alcohol effects - incidence and understanding in the Cape. SAMJ 1985; 68:779-780.

24. Van Rensburg LJ. The Fetal Alcohol Syndrome. SA Fam Prac 1985; 33:207-12.

25. World Health Organisation. Use and interpretation of anthropometric indicators of nutritional status. Bulletin of the World Health Organisation 1986; 64:924-41.

26. World Health Organisation. Oral Health Surveys. Basic Methods. 4th edition. Geneva: WHO,1997.

27. Silness J, Löe H. Periodontal Disease in Pregnancy. II. Correlation between oral hygiene and periodontal conditions. Acta Odontol Scand 1964; 22: 121.

28. Greene JC. General principles of epidemiology and methods for measuring prevalence and severity in periodontal disease. In: Genco RJ, Goldman HM, Cohen DW, Eds. Contemporary Periodontics. St Louis: C.V. Mosby Co; 1990:97-105.

29. Carter HG, Barnes GP. The Gingival Bleeding Index. J Periodontol 1974; 45:801.

30. Klein H, Palmer CE, Knutson JW. Studies on dental caries. I. Dental status and dental needs of elementary school children. Public Health Rep1938; 53:751.

31. Gruebbel AO. A measurement of dental caries prevalence and treatment service for deciduous teeth. J Dent Res 1994; 23:163.

32. Roed-Petersen B, Renstrup G. A topographical classification of the oral mucosa suitable for electronic data processing. Its application to 560 leukoplakias. Acta Odontol Scand 1968; 27:681-95.

33. Jones KL, Smith DW, Streissguth AP, et al. Outcome in offspring of chronic alcoholic women. Lancet 1974; 1(7866) 1076-78.

34. Jones KL, Smith DW, Ulleland CN, et al. Pattern of malformation in offspring of chronic alcoholic mothers. Lancet 1973; 1:1267-71.

35. Hanson JW, Streissguth AP, Smith DW. The effects of moderate alcohol consumption during pregnancy on fetal growth and morphogenesis. J Paediatr 1978; 92:457-60.

36. Jackson IT, Hussain K. Craniofacial and oral manifestations of Fetal Alcohol Syndrome. Plast Reconstr Surg 1990; 85:505-12.

37. Majewski F. Clinical symptoms in patients with fetal alcohol syndrome. In: Alcohol, pregnancy and the developing child. Eds. Spohr H-L, Steinhausen H-C. Cambridge: Cambridge University Press; 1996: 15-40. 
38. Spohr HL, Willms J, Steinhausen HC. Prenatal exposure and long-term developmental consequences. Lancet 1993; I: 907-910.

39. Streissguth AP, Grant TM, Barr HM, et al. Cocaine and the use of alcohol and other drugs during pregnancy. Am J Obstet Gynecology 1991; 164:1239-43.

40. Korányi G, Vitéz M, Czeizel A. Quantitative measurement of facial traits. In Czeizel A, Ed. Fetal Alcohol Syndrome. Budapest: Medicina; 1981: 46-62.

41. Abel EL. Fetal alcohol syndrome and fetal alcohol effects. New York: Plenum Press; 1984:15-85.

42. Vitéz M, Korányi G, Gönczy E, et al. A semiquantative score system for epidemiological studies of fetal alcohol syndrome. Am J Epidemiol 1984; 119:301-8.

43. Day NL, Jasperse MS, Richardson GA, et al. Prenatal exposure to alcohol. Effect on infant growth and morphologic characteristics. Pediatrics 1989; 84:536-41.

44. Astley SJ, Clarren SK, Little RE, et al. Analysis of facial shape in children gestationally exposed to marijuana, alcohol, and or cocaine. Pediatrics 1992; 89:67-77.

45. Aase JM. Clinical recognition of FAS: difficulties of detection and diagnosis. Alcohol Health Res World 1994: 18:5-9.

46. Astley, SJ, Clarren SK. A fetal alcohol screening tool. Alcohol Clin Exp Res 1995; 19:1565-71.

47. Astley SJ, Clarren SK. A case definition and photographic screening tool for the facial phenotype of fetal alcohol syndrome. J Pediatr 1996; 129:33-41.

48. Astley SJ, Clarren SK. Measuring the facial phenotype of individuals with prenatal exposure: correlations with brain dysfunction. Alcohol Alcoholism 2001; 36:147-59.

49. Brandt J. Kopfumfang und Gehirnentwicklung. Klinische Wochenschrift 1981; 59:995-1007.

50. Potter RH, Nance WE. A twin study of dental dimensions: I. Discordance, asymmetry and mirror imagery. Am J Phys Anthrop 1976; 44:391-5.

51. Alberch P. Developmental constraints in evolutionary processes. In: Evolution and development. J.T. Bonner, Ed. Berlin: Springer; 1982: 313-332.

52. Katz MT. Odontogenic mechanisms: The middle road of evolution. In: Evolution and development. J.T. Bonner, Ed. Berlin: Springer; 1982: 207-12.

53. Cheverud JM. Quantitative genetics and developmental constraints on evolution by selection. J Theoret Biol 1984; 110: 155-71.

54. Van Valen L. A study of fluctuating asymmetry. Evolution 1962; 16:125-42.

55. Hoyme HE. Minor anomalies: diagnostic clues to aberrant human morphogenesis. Genetica 1993; 89: 307-315.

56. Kieser JA, Groeneveld HT. Fluctuating Odontometric Asymmetry in an Urban South African Black Population. J Dent Res 1988; 67:1200-1205.

57. Jones KL. Smith's recognizable patterns of hand malformation, 4th edition. Philadelphia: WB Saunders Co; 1988: 662-81.

58. Spranger J, Bernirschke K, Hall JG. Errors of morphogenesis: concepts and terms. J Paediatr 1982; 100:160-65.

59. Church MW, Gerkin KP. Hearing disorders in children with fetal alcohol syndrome: findings from case reports. Pediatrics 1988; 82:147-54.

60. Church MW, Eldis F, Blakley BW, et al. Hearing, language, speech, vestibular and dentofacial disorders in fetal alcohol syndrome. Alcohol Clin Exp Res 1997; 21: 227-37.

61. Coles CD, Brown RT, Smith IE, et al. Effects of prenatal exposure at school age. I. Physical and cognitive development. Neurotoxicol Teratol 1991; 13:357-67.

62. Downs MP, Jafek B, Wood RP. Comprehensive treatment of children with recurrent serious otitis media. Otolaryngol Head Neck Surg 1981; 89:658-65.

63. Streissguth AP, Clarren SK, Jones KL. Natural history of the fetal alcohol syndrome: a 10-year follow-up of 11 patients. Lancet 1985; ii:85-91.

64. Hwang SJ, Beaty TH, Panny SR, et al. Association study of transforming growth factor alpha (TGFa) Taq1 polymorphism and oral clefts: indication of gene-environment interaction in a population-based sample of infants with birth defects. Am J Epidemiol 1995; 141:629-36. 
65. Duester G. A hypothetical mechanism for fetal alcohol syndrome involving ethanol inhibition of retinoic acid synthesis at the alcohol dehydrogenase step. Alcoholism Clin Exp Res 1991; 15:568-72.

66. Duester G, Shean ML, McBride MS, et al. Retinoic acid response element in the human alcohol dehydrogenase gene ADH3: Implications for regulation of retinoic acid synthesis. Mol Cell Biol 1991; 11:1638-46.

67. Niebyl JR, Blake DA, Rocco LE, et al. Lack of maternal metabolic, endocrine and environmental influences in the aetiology of cleft lip with or without cleft palate. Cleft Palate J 1985; 22:20-8.

68. Werler MM, Lammer EJ, Rosenberg L, et al. Maternal alcohol use in relation to selected birth defects. Am J Epidemiol 1991; 134:691-8.

69. Munger RG, Romitti PA, Daack-Hirch S, et al. Maternal alcohol use and Risk of Orofacial Cleft Birth Defects. Teratology 1996; 54:7-33.

70. Arendorf TM, van der Ross R. Oral soft tissue lesions in a black pre-school South African population. Comm Dent Oral Epidemiol 1996; 24:296-7.

71. Pimlott FL, Howley TP, Nikiforuk G, et al. Enamel defects in prematurely born low birth weight infants. Paediatr Dent 1985; 7:218-23.

72. Kim Seow W, Humphreys C, Tudehope DI. Increased prevalence of developmental defects in low birth-weight, prematurely born children: a controlled study. Pediatric Dentistry 1978; 9:221-5.

73. Matee M, van't Hof M, Maselle S, et al. Nursing caries, linear hypoplasia, and nursing and weaning habits in Tanzanian infants. Community Dent Oral Epidemiol 1994; 22:289-93.

74. Hargreaves JA, Cleaton-Jones PE, Williams P. Hypocalcification and hypoplasia in permanent teeth of children from different ethnic groups in South Africa assessed with a new index. Adv Dent Res 1989; 3:126-131.

75. Nelson JA, Miller DJ, Cardo VA, et al. Fetal alcohol syndrome: review of the literature and case report. J Am Dent Assoc 1990; 56:24-7.

76. Glick P. Mineralization of teeth: prenatal and post natal nutrient requirements. In Wei SHY (ed). Paediatric Dental Care. New York: Medcom Inc; 1987:106-117.

77. Winter G. Maximal nutritional requirements in relation to subsequent development of teeth in children. J Hum Nutr 1976; 30:93-103.

78. Dummer PMH, Kingdon A, Kingdon R. Distribution of developmental defects in tooth enamel by tooth type in 11-12 year old children in South Wales. Comm Dent Oral Epidemiol 1986; 14:341-44.

79. Department of Health: National Oral Health Survey. Pretoria, 2003.

80. Demirjian, A, Buschang PH, Tanguay R, et al. Interrelationships among measures of somatic, skeletal, dental and sexual maturity. Am J Orthod 1985; 88: 433-8.

81. Hartshorne JE, Carstens IL, Louw AJ, et al. Rural oral health care programme - An epidemiological survey of farmworkers in the Boland. Part III: Dental status and treatment needs. CHASA 1993; 4: 86-91.

82. Barnett R, Shusterman S. Fetal alcohol syndrome: Review of the literature and reports of cases. J Am Dent Assoc 1985; 111:591-3.

83. Webb S, Hochberg MS, Sher MR. Fetal alcohol syndrome - Report of a case. J Am Dent Assoc 1988; 116: 96-98.

84. Majewski F, Goecke T. Alcohol embryopathy: Studies in Germany. In: Fetal Alcohol Syndrome. Volume 2: Human Studies, E.L.Abel, Ed. Boca Raton Florida: CRC Press; 1982:155-165.

85. Steinhausen HC, Spohr HL. Fetal alcohol syndrome. Adv Clin Child Psychol 1986; 9:217-243.

86. Wood RE. Fetal alcohol syndrome: Its implications for dentistry. J Am Dent Assoc 199795: 596-99.

87. Linder-Aronson S, Rølling S. Preventive orthodontics. In: Pedodontics: a systematic approach. BO Magnusson, Ed. Copenhagen: Munksgaard; 1981: 259.

88. Riekman GA. Oral findings of fetal alcohol syndrome patients. J Can Dent Assoc 1984; 11:841-42. 
About the Authors

\section{Naldoo, BDS, LDS.RCS, MDPH, DDPH.RCS, MChD, Pho}

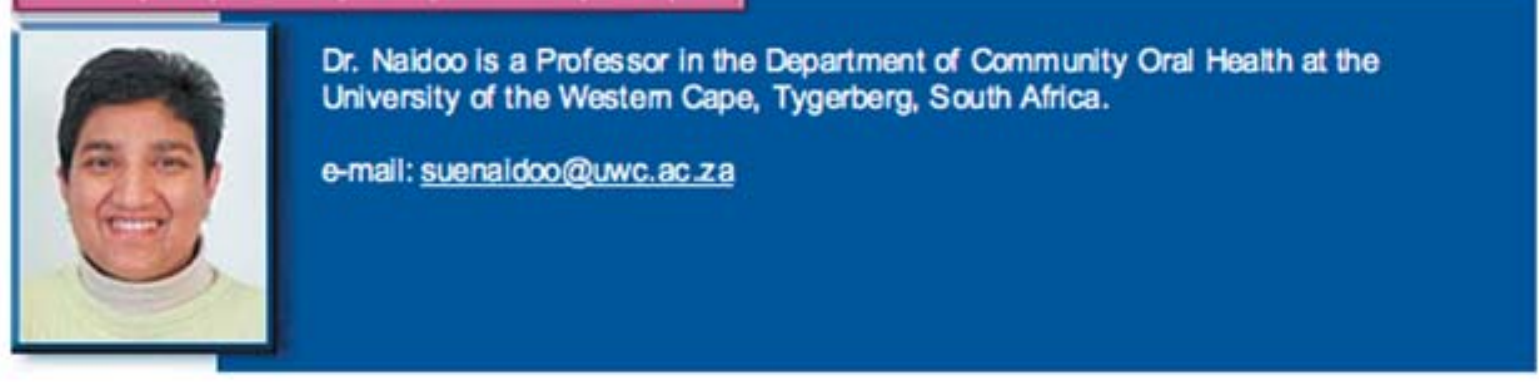

\section{Usuf Chikte, BChD, MSc, DHSM, MDent}

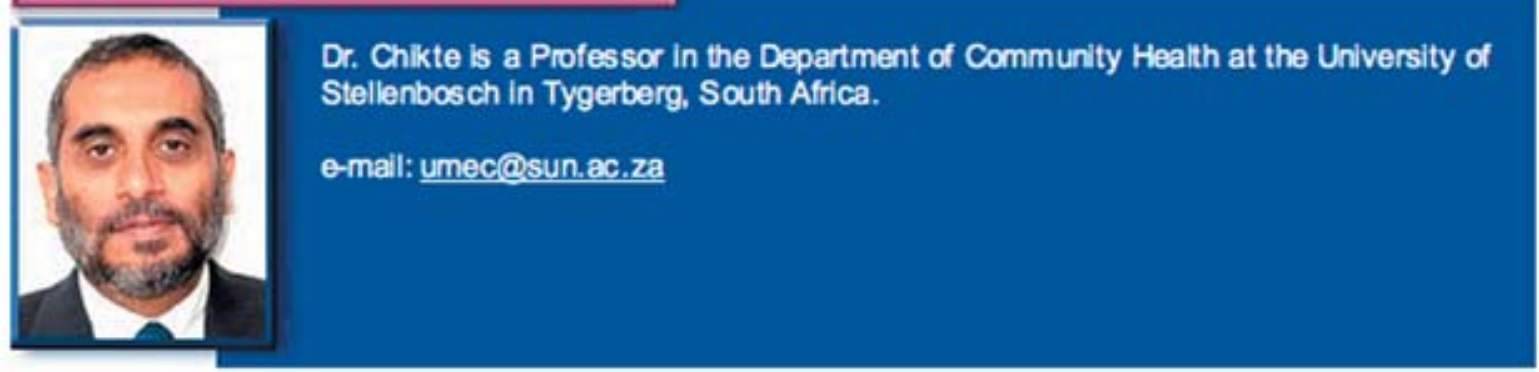

\section{Ria Laubscher, BComm}
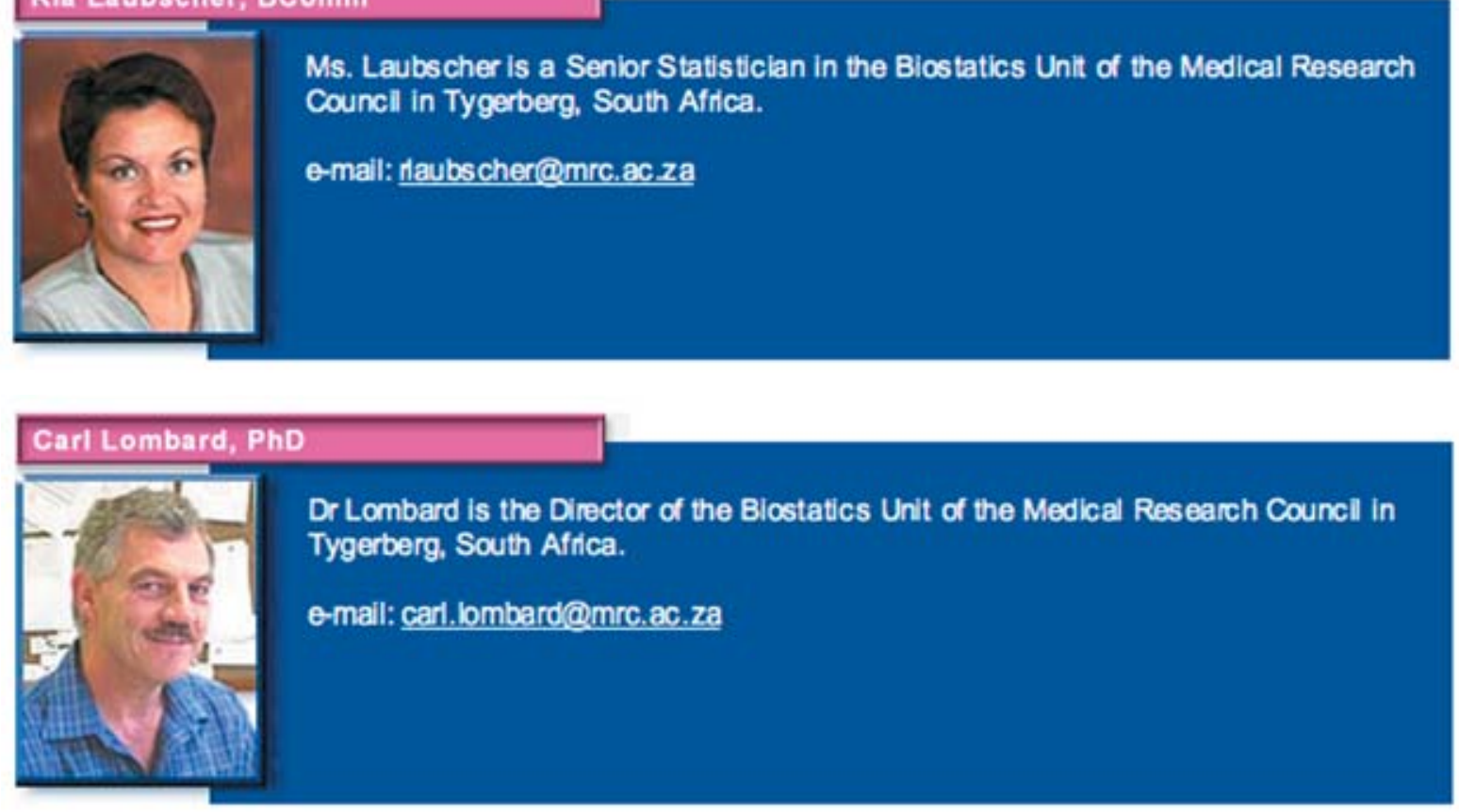